\title{
EFFECT OF DEDICATED MECHANICAL SUBCOOLER SIZE AND GAS COOLER PRESSURE CONTROL ON TRANSCRITICAL $\mathrm{CO}_{2}$ BOOSTER SYSTEMS
}

\author{
P. D’Agaro, M.A. Coppola, G. Cortella* \\ DPIA, University of Udine, Italy \\ giovanni.cortella@uniud.it \\ ${ }^{(*)}$ Corresponding author
}

\begin{abstract}
Dedicated Mechanical Subcooling (DMS) is one of the most investigated and effective strategies applied to increase the performance of $\mathrm{CO}_{2}$ commercial refrigeration systems in transcritical operation. Further performance benefits can be obtained by a reduction of the gas cooler pressure of the main cycle at transcritical conditions. In this work the most important parameters for the design and operation of such a system, i.e. the DMS cooling capacity, the subcooling degree and the gas cooler pressure, are considered and their effect on the annual energy use of the plant is estimated in warm and hot climate conditions by means of a validated model. DMS is also compared to the parallel compression scheme and subcooling performed through a water chiller dedicated to HVAC. DMS results to be the most effective solution among those investigated, and the choice of the best design and operating parameters allows further energy saving and cost reduction.
\end{abstract}

Keywords: $\mathrm{CO}_{2}$, Natural Refrigerants, Commercial refrigeration, Dedicated Mechanical Subcooling, Optimization

\begin{tabular}{|c|c|c|c|}
\hline \multicolumn{4}{|c|}{ NOMENCLATURE } \\
\hline & General & & \\
\hline B & Basic transcritical booster system & BPC & Booster system with Parallel Compressor \\
\hline BDMS & B system with DMS & $p$ & Pressure [bar] \\
\hline $\mathrm{COP}$ & Coefficient Of Performance & $p_{I N T}$ & Intermediate pressure [bar] \\
\hline DMS & Dedicated Mechanical Subcooling & $Q$ & Heat flow $[\mathrm{kW}]$ \\
\hline HVAC & Heating, Ventilation, Air Conditioning & BSC & Booster system with HVAC Subcooler \\
\hline GC & Gas Cooler & $t$ & Temperature $\left[{ }^{\circ} \mathrm{C}\right]$ \\
\hline GWP & Global Warming Potential & $W$ & Compressor power [kW] \\
\hline $\mathrm{LT}$ & Low Temperature & $w$ & Specific compressor work $[\mathrm{kJ} / \mathrm{kg}]$ \\
\hline MT & Medium Temperature & $x_{\text {rec }}$ & Receiver inlet vapour quality [-] \\
\hline$\dot{m}$ & Refrigerant flow rate $[\mathrm{kg} / \mathrm{s}]$ & $\Delta h_{\text {sub }}$ & Subcooling degree, enthalpy [kJ/kg] \\
\hline OBDMS & Optimised BDMS & $\Delta t_{\text {sub }}$ & Subcooling degree, temperature $[\mathrm{K}]$ \\
\hline & Subscripts/Superscripts & & \\
\hline act & activation & $L S$ & Low Stage \\
\hline app & approach & $\max$ & maximum \\
\hline ext & external/outdoor & $S C$ & Subcooler \\
\hline evap & evaporator & set & setpoint \\
\hline$G C$ & Gas Cooler & sub & subcooling \\
\hline$H S$ & High Stage & opt & optimal \\
\hline & Greek symbols & & \\
\hline$\alpha$ & $\begin{array}{l}\text { DMS to main cycle cooling capacity } \\
\text { ratio (eq. } 10 \text { ) }\end{array}$ & $\varphi$ & Flow rate ratio parameter (eq. 5) \\
\hline$\beta$ & Compression ratio & $\psi$ & $\begin{array}{l}\text { Vapour quality complementary parameter } \\
\text { (eq. 6) }\end{array}$ \\
\hline
\end{tabular}




\section{INTRODUCTION}

The phase down schedule for the hydro-fluorocarbons, established worldwide by the Kigali Amendment to the Montreal Protocol and forced in Europe by the EU regulation 517/2014 on fluorinated greenhouse gases, has promoted the use of natural refrigerants as long term solutions to the global warming issue. $\mathrm{CO}_{2}$ is one of the most promising natural working fluids in the commercial refrigeration sector; its Global Warming Potential $($ GWP $)=1$ and high safety characteristics (A1 ASHRAE classification) make it suitable for supermarket refrigeration systems which are characterized by large amounts of refrigerant and large direct environmental impact related to refrigerant leakage. Actually a $\mathrm{CO}_{2}$ system can outperform the HFC-based refrigerating units when operating at subcritical condition. As soon as the outdoor temperature increases and the transcritical operation is established, a drastic reduction of the energy efficiency is recorded. An imaginary geographic boundary, named $\mathrm{CO}_{2}$ equator, was introduced to identify the latitude below which the basic transcritical booster system has lower performance than HFC-based systems and thus introduces higher indirect $\mathrm{CO}_{2}$ emissions [1]. In the last decade, many efforts have been addressed to extend the convenience of use of $\mathrm{CO}_{2}$ in warm climates. Several technologies and alternative plant schemes have been studied and tested, showing that improvements of the performance in $\mathrm{CO}_{2}$ refrigeration plants can be achieved. As a result, $\mathrm{CO}_{2}$ direct expansion systems are currently popular solutions for commercial refrigeration and the number of stores using $\mathrm{CO}_{2}$ transcritical refrigeration technology has been increasing substantially all over the world, especially in Europe, where 14,000+ stores are equipped with this type of system [2].

Subcooling the refrigerant exiting the gas cooler is one of the most widespread solutions among the several ones available, and has been recently investigated by many researchers [3]. When dealing with booster systems, subcooling permits to reduce the amount of flash gas production at the liquid receiver and, in standard schemes, to reduce the refrigerant quality at the inlet of the expansion device, which in turn yields an increase of the cooling capacity.

The easiest and long-established way to perform subcooling is through the employment of an "internal heat exchanger (IHX)". The IHX can be placed at various positions in the system, which is fed, for instance, by the gas at the exit of the gas cooler, by the liquid at the exit of the receiver or by the vapour at the exit of the evaporator $[4,5,6,7,8]$, giving rise also to configurations once known as "economizer" or "suction vapor injection". Nonetheless, the use of IHX can be combined with ejectors [9] or expanders [10].

The opportunity to uncouple the cooling power generation and the use for subcooling can be exploited by benefitting of cold water storage, as shown by Polzot et al [11] with regard to a fire prevention water reservoir. Cortella et al. investigated another plant scheme where the cooling power demand can be satisfied by coupling the refrigeration with the HVAC systems, when this is available [12]. This solution has showed lower performance than other configurations such as the parallel compression of the flash gas, but it can give rise to an economic advantage thanks to the low investment costs.

Nevertheless, in addition to the solutions just mentioned, subcooling is being increasingly achieved by using a Dedicated Mechanical Subcooling (DMS) system, which consists of a dedicated refrigerating unit that provides the cooling power through direct expansion in a heat exchanger or, sometimes, through a secondary fluid. This solution appears to be recommended at high rejection temperature and low evaporating level, and the use of natural fluids like R290 is widespread [13]. Hafner and Hemmingsen [14] evaluated the theoretical performance of a R290 DMS system with a maximum capacity equal to 30\% of the nominal capacity of the $\mathrm{CO}_{2}$ main cycle, i.e. a single-stage with flash receiver and internal heat exchanger. They estimated an increase of the COP up to $+15.4 \%$ in relation to the standard booster system and $+6 \%$ in relation to a R404A direct expansion plant. Llopis et al. [15] simulated the use of a R290 DMS in both single and double stage $\mathrm{CO}_{2}$ plants, at $-30,-5$ and $5{ }^{\circ} \mathrm{C}$ evaporating temperature. In their computations, they considered a maximum value of 7.5 $\mathrm{K}$ for the subcooling degree and they predicted increments up to around $20 \%$ at outdoor temperature higher than $25^{\circ} \mathrm{C}$ and maximum capacity gain of $28.8 \%$. They also quantified the effect of an optimization of the gas cooler pressure, which can be effectively reduced of up to 12 bar when using DMS in a booster cycle at -30 evaporating temperature and $35{ }^{\circ} \mathrm{C}$ outdoor temperature. Still from the thermodynamic analysis of a DMS coupled to a single stage cycle operating at three different evaporating levels $\left(-15,-5\right.$ and $\left.5^{\circ} \mathrm{C}\right)$ and outdoor temperature spanning from 20 to $40^{\circ} \mathrm{C}$, Dai et al. [16] also demonstrated that a maximum COP is achieved at a corresponding optimum discharge pressure and subcooling temperature. By comparing different DMS refrigerants, the best improvement resulted with R717, although the differences among the several fluids were 
small, which suggests to employ safer fluids. The conclusion was that the mechanical subcooling is recommended for the cases with higher rejection temperatures and lower evaporation levels. Also exergy analyses have been performed on this application: Liu et al. [17] made a theoretical comparison among various R290 mechanical subcooling systems applied to a two-stage transcritical $\mathrm{CO}_{2}$ cycle with intercooler. They obtained the maximum coefficient of performance (COP) under optimal subcooling degree and compressor discharge pressure.

With regard to experimental results on single evaporating temperature plants, Nebot-Andrés et al. [18] carried out an experimental study of a single stage double-throttling $\mathrm{CO}_{2}$ refrigeration system (4 kW) with a R1234yf DMS system $(0.7 \mathrm{~kW})$. The performance of the system was evaluated at constant compressor speed and $0^{\circ} \mathrm{C}$ of evaporation temperature for two gas-cooler exit temperatures $\left(30.2\right.$ and $40^{\circ} \mathrm{C}$ ). At the optimum gas-cooler pressure, increments of the COP equal to $22.8 \%$ at $30.2^{\circ} \mathrm{C}$ and $17.3 \%$ at $40^{\circ} \mathrm{C}$ were measured. Furthermore, Llopis et al. [19], using the same plant, extended the experimentation to another evaporating level $\left(-10^{\circ} \mathrm{C}\right)$ and to a further gas-cooler exit temperature of $24^{\circ} \mathrm{C}$. They found that the optimum heat rejection pressures are reduced using the DMS (up to 8 bar) and measured COP increments from 6.9 to $30.3 \%$.

Carbon dioxide is a very promising refrigerant especially for supermarket applications, where two temperature levels are needed and booster systems are used. Gullo et al. [20] simulated a R290 DMS system for a small sized supermarket at the warm climate conditions of Valencia and Athens. Two cooling capacities for the DMS were considered, to achieve $7^{\circ} \mathrm{C}$ or $15^{\circ} \mathrm{C}$ at the $\mathrm{CO}_{2}$ subcooler exit and a COP increase around $23 \%$ in relation to the booster with flash gas valve was obtained for both configurations. Beshr et al. [21] and Bush et al. [22] simulated and then experimentally validated a prototype of booster system for supermarket applications with DMS working with R134a and water-glycol mixture as heat transfer fluid. In the experimental verification they observed the predicted effects, among which a large increment of the overall COP, namely $33.5 \%$ at $29^{\circ} \mathrm{C}$ of rejection temperature and $36.7 \%$ at $35^{\circ} \mathrm{C}$. Mazzola et al. [23] provided data from real plants comparing different technologies, i.e. DMS, water chiller and groundwater source. The groundwater source performed best as expected, however subcooling showed to be very effective especially in hot climate conditions. CatalánGil et al [24] carried out an analysis, based on close-to-reality thermodynamic models, which compares the energy performance of a $\mathrm{CO}_{2}$ booster system with internal heat exchanger (to perform subcooling) and a $\mathrm{CO}_{2}$ booster system with R290 DMS with the reference $\mathrm{CO}_{2}$ booster with parallel compression. This particular scheme doesn't include a flash gas valve, thus the subcooler is activated when the outdoor temperature exceeds $8^{\circ} \mathrm{C}$ and the vessel pressure is controlled in order to avoid any flash-gas production. They identify the operating conditions which optimize the COP over an outdoor temperature range from $0^{\circ} \mathrm{C}$ to $40^{\circ} \mathrm{C}$ and conclude that DMS performs the best at temperature higher than $22^{\circ} \mathrm{C}$. From the calculation of the annual energy consumption for hundreds of locations in Europe and in Asia, it results that DMS is recommended only for warm and hot regions, leading reductions up to $3 \%$, with respect to the reference system, e.g. in Southern Europe, and up to $6 \%$ in India. DMS appears then to be an effective solution to improve the performance of $\mathrm{CO}_{2}$ systems, and its control rules need investigation to identify possible optimal set points, which are usually encountered in refrigerating cycles where subcooling is implemented [25].

A comprehensive model was thus built in the TRNSYS environment [26], which includes the transcritical $\mathrm{CO}_{2}$ booster refrigeration unit, as well as the display cabinets and cold rooms, and the possibility of mutual heat exchange with the HVAC plant to perform heat recovery $[27,28]$. The model has been calibrated and validated against the field data gathered during a whole year from the monitoring of an actual refrigerating system in operation in a small sized supermarket located in Northern Italy as described by Cortella et al. [29] and D’Agaro et al. [30].

In this paper, the performance of this booster system with a R1234yf DMS unit is analysed. Among the most promising fluids for the DMS there are HFOs and other flammable natural refrigerants like propane, isobutane, or propylene. All of them are well suitable fluids for the DMS unit, a lot of literature and practical applications is available, but showing that the major influence in the global COP comes from the control of the system rather than from the refrigerant used in the DMS [16]. Safety issues related to flammability of A3 fluids pose critical constrains to an indoor installation of the units. Thanks to its A2L flammability class, R1234yf benefits of a pretty higher charge limit for indoor plants. Considered that R1234yf offers a remarkably low global warming potential $\left(\mathrm{GWP}_{100}=4\right)$, it appears as a viable and more easily feasible solution for DMS [18]. 
The optimal operating conditions of the overall system are identified and the energy saving produced by the control of the gas cooler pressure, as a function of the subcooling degree in addition to the outdoor temperature, has been estimated.

Given that the subcooling degree depends on the available cooling capacity of the subcooler, a procedure to identify its most suitable size on the basis of the annual energy saving is presented. The performance of the $\mathrm{CO}_{2}$ booster with DMS is compared with that of alternative plant schemes, i.e. parallel compression and subcooling by means of the HVAC chiller, underlining how the benefits change at different warm and hot climates.

\section{REFRIGERATION SYSTEM MODEL}

The commercial refrigeration system considered in this work is an existing monitored one in operation in a small supermarket, of approximately $1200 \mathrm{~m}^{2}$, located in Modena (northern Italy). The supermarket has undergone refurbishment in the framework of the FP7 European Project CommONEnergy [31] and the new generation refrigeration plant installed is composed of a transcritical $\mathrm{CO}_{2}$ booster system and closed refrigerated display cabinets, both for chilled and frozen food.

The entire refrigeration system with all its components, such as display cabinets, cold rooms and the $\mathrm{CO}_{2}$ refrigeration unit, has been described by in-house mathematical models developed in the TRNSYS environment as illustrated in detail in Polzot et al. [11]. This allows to carry out simulations with time dependent input variables of such a complex system, including mutual interactions with the building and with the HVAC plant. The peak cooling capacity of display cabinets and cold rooms is equal to $39.7 \mathrm{~kW}$ for the Medium Temperature (MT) level and to $6.8 \mathrm{~kW}$ for the Low Temperature (LT).

The model used in this paper implements a basic transcritical $\mathrm{CO}_{2}$ booster cycle with liquid receiver and flash gas expansion valve. The refrigerant properties at the principal states of thermodynamic cycle are calculated by linking our in-house routines in the TRNSYS environment to the CoolProp libraries [32]; the instantaneous mass flow rate is calculated in order to satisfy the cooling capacity estimated by the time dependent models of the display cabinets and cold rooms [11], and it defines the status of the compressor racks; the compressors themselves have been described using the manufacturer correlations, while the heat exchangers are modelled via the approach temperature.

The detailed description of the refrigeration system, including information on the configuration of the LS and HS compressor racks and activation rules, is given in D'Agaro et al. [30], where a thorough calibration and validation process of the model and control rules has been carried out against the yearly field data available from the real plant. The schematic and the thermodynamic cycle in a $(p-h)$ chart are given if Figs. 1 and 2, while the values of the main design parameters and settings are recalled in Table 1.

The actual plant allows subcooling at the exit of the gas cooler by exchanging heat with chilled water provided by the HVAC plant [12]. In the present work, a Dedicated Mechanical Subcooler (DMS), that consists of a single-stage cycle working with R1234yf as refrigerant, has been adopted and included in the model, in order to exploit the energy improvements from the use of a dedicated subcooler, free from the penalties of HVAC coupling.

The thermodynamic cycle of the subcooler unit has been modelled according to the parameter values reported in Table 1 (DMS unit) and taking into account the compressor operating limits (compressor envelope). Standalone simulations have been carried out in order to infer the COP as a continuous function of the outdoor temperature and evaporating level. A set of $\mathrm{COP}_{\mathrm{DMS}}$ profiles, each one for a certain evaporating temperature, is shown in Fig. 3.

The effects of subcooling on the $\mathrm{CO}_{2}$ cycle are depicted in Fig. 2 (BDMS): compared to the basic cycle (B), the subcooling $\left(\Delta h_{s u b}\right)$ reduces the exit temperature at the high stage pressure and in turn the vapour quality at the receiver. 


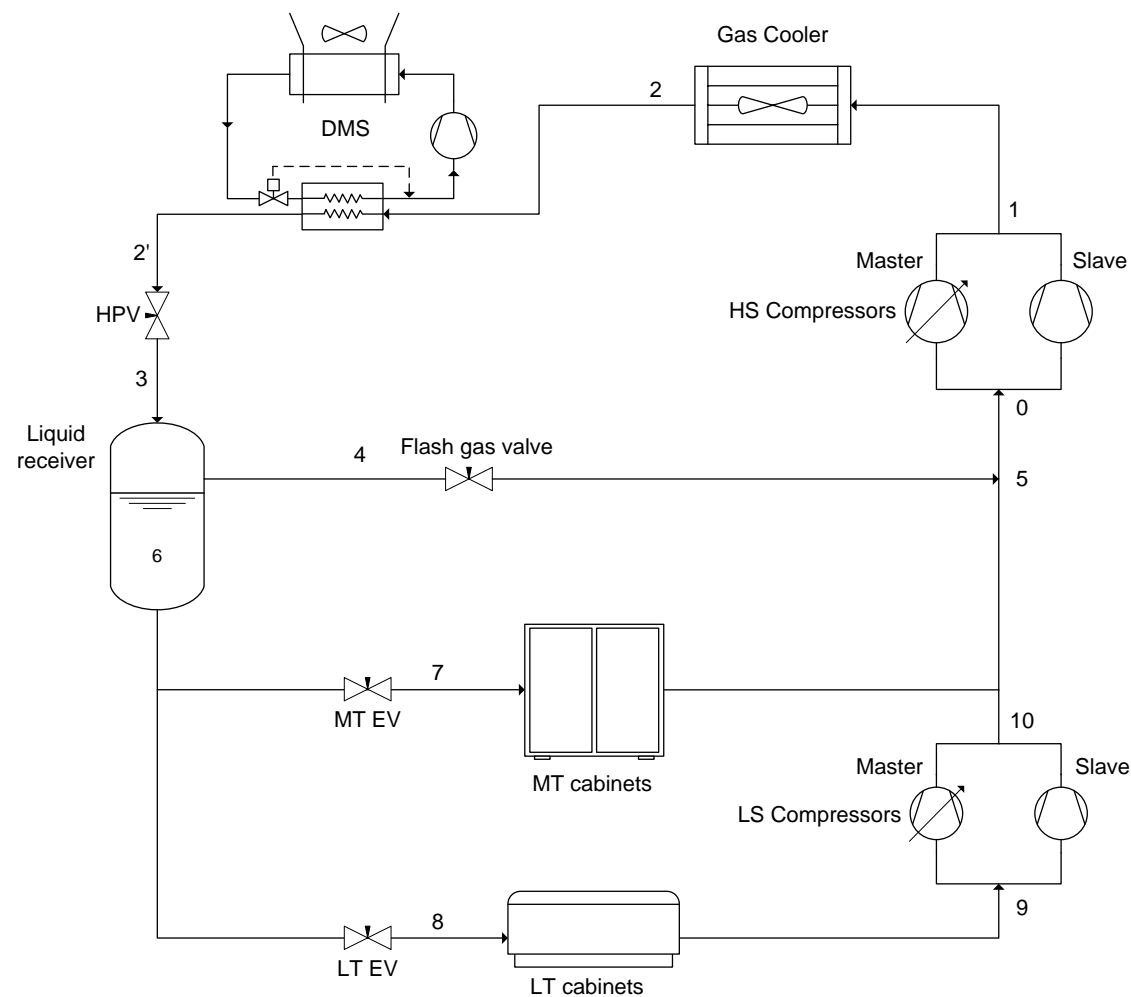

Figure 1: Schematic diagram of the transcritical $\mathrm{CO}_{2}$ booster system with DMS (BDMS and OBDMS) investigated.

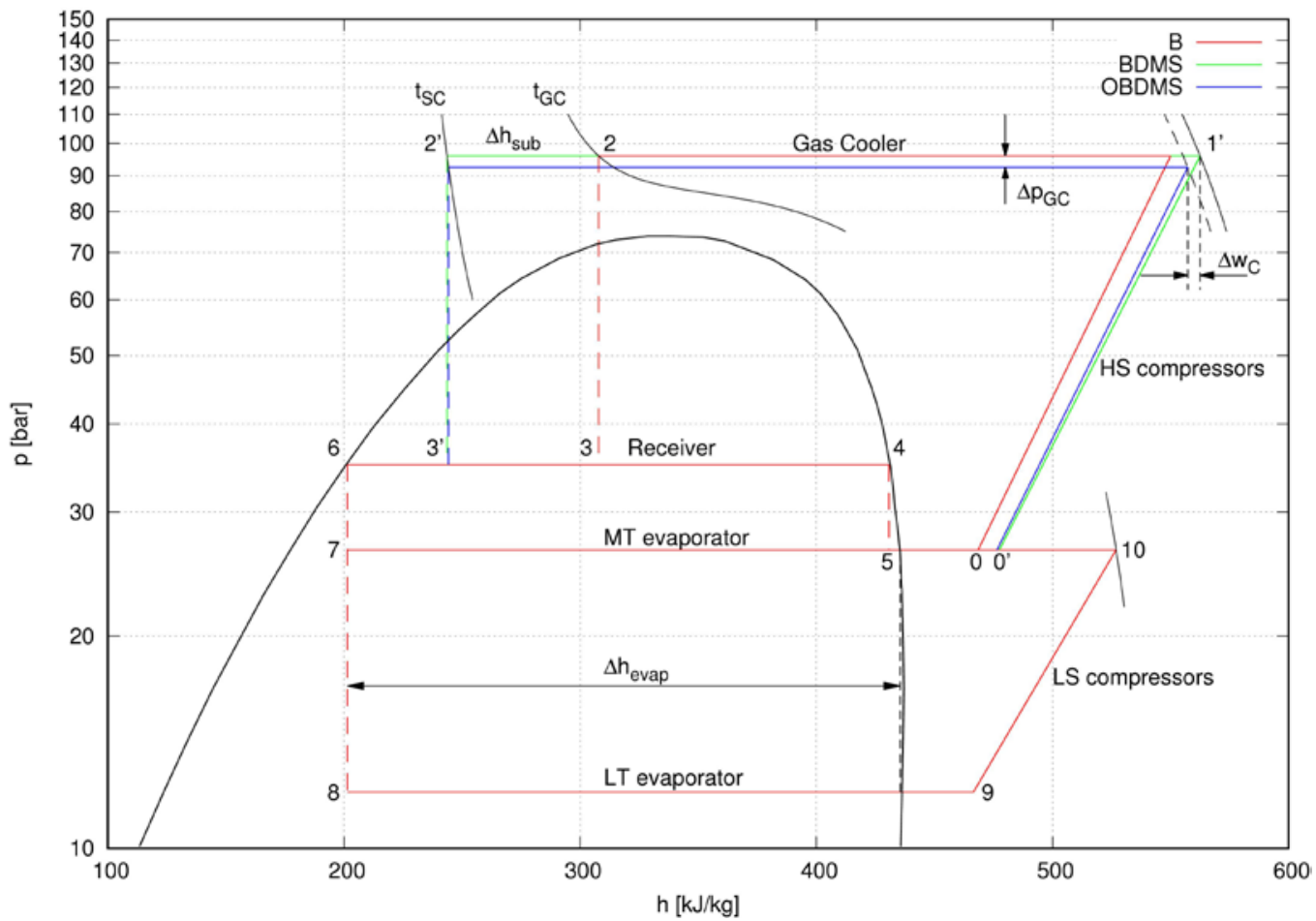

Figure 2: Thermodynamic cycle in a (p-h) diagram of a transcritical $\mathrm{CO}_{2}$ booster system in the following configurations: a) Booster with flash gas valve (B); b) Booster with DMS (BDMS); C) Optimised Booster with DMS (OBDMS). 
Table 1. Main design parameters for the $\mathrm{CO}_{2}$ booster System (B) and for DMS unit.

\begin{tabular}{|c|c|c|}
\hline \multicolumn{3}{|c|}{$\mathrm{CO}_{2}$ booster System } \\
\hline Parameter & Unit & Value \\
\hline LT evaporating temperature & ${ }^{\circ} \mathrm{C}$ & -35 \\
\hline MT evaporating temperature & ${ }^{\circ} \mathrm{C}$ & -10 \\
\hline Minimum condensing temperature at subcritical conditions & ${ }^{\circ} \mathrm{C}$ & 6 \\
\hline Liquid receiver pressure & bar & 35 \\
\hline Subcooling at subcritical conditions & K & 3 \\
\hline Gas Cooler/Condenser approach temperature difference & K & 4 \\
\hline LT superheating (up to actual suction temperature) & K & 30 \\
\hline MT superheating (up to actual suction temperature) & K & 20 \\
\hline LS Low Stage compressors & \multicolumn{2}{|c|}{$\begin{array}{l}\text { Bitzer 2JSL-2K } \\
\text { Bitzer 2KSL-1K }\end{array}$} \\
\hline HS High Stage compressors & \multicolumn{2}{|c|}{$\begin{array}{l}\text { Bitzer 4FTC-20K } \\
\text { Bitzer 4JTC-15K }\end{array}$} \\
\hline $\begin{array}{l}\text { Subcooler set point temperature } t_{S C \text {, set }} \\
\text { (Specific for BDMS and OBDMS) }\end{array}$ & ${ }^{\circ} \mathrm{C}$ & 15 \\
\hline \multicolumn{3}{|l|}{ DMS unit } \\
\hline Parameter & Unit & Value \\
\hline Evaporator approach temperature (minimum value) & K & 5 \\
\hline Condenser approach temperature & K & 10 \\
\hline Superheating & K & 10 \\
\hline Compressor & \multicolumn{2}{|c|}{ Emerson ZB66KCE-TFE } \\
\hline Compressor global efficiency & \multicolumn{2}{|c|}{$\eta_{D M S}=-0,07 \beta^{2}+0.4796 \beta-0.1234$} \\
\hline
\end{tabular}

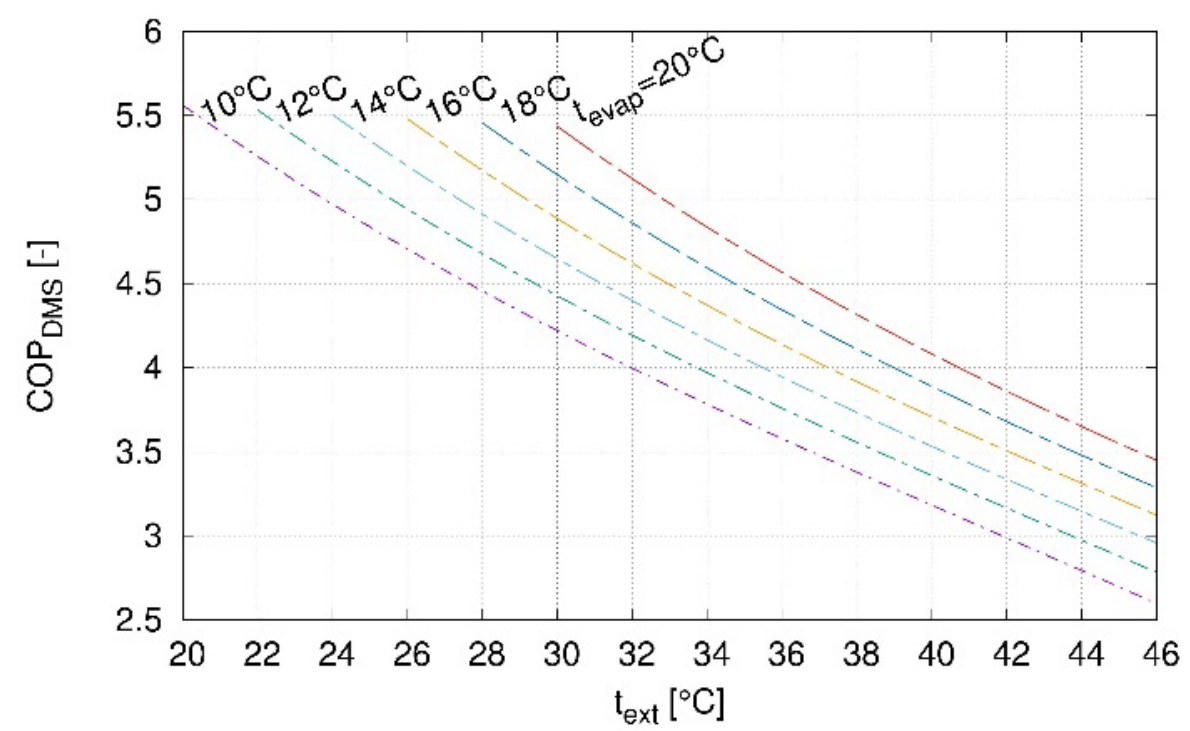

Figure 3: COP of the DMS unit against outdoor temperature, for a set of fixed evaporating temperatures.

The coupling between the subcooler and the booster system (BDMS) is implemented as follows:

- the high pressure $p_{G C}$ of the main cycle, in transcritical conditions, follows the control rule:

$p_{G C}=\max \left[75 ;\left(2.56 t_{G C}-1.247\right)\right][\mathrm{bar}]$

which optimizes the COP of the basic booster system with flash gas expansion valve (B) [11];

- The evaporating temperature of the DMS cycle $t_{\text {evap,DMS }}$ is set at: 
$t_{\text {evap, DMS }}=\max \left[\left(t_{S C, \text { set }}-\Delta t_{\text {app }, S C}\right) ; t_{\text {evapDMS, lim, }}\right]$

where $t_{S C \text {, set }}$ is the set point value for the temperature at the exit of the subcooler, $\Delta t_{a p p, S C}$ is the minimum evaporator approach temperature (values in Table 1) and $t_{\text {evap,DMs,lim }}$ is imposed, for a given condensing temperature, by the compressor operating limits.

- Once the evaporating level has been fixed and the DMS size is known, a check is carried out to verify if the outdoor temperature and the available DMS cooling capacity allow to reach the set point temperature $t_{S C \text {,set }}$, otherwise the achievable $\mathrm{CO}_{2}$ exit temperature $t_{S C}$ is calculated.

The choice of $15^{\circ} \mathrm{C}$ as the minimum subcooler outlet temperature $t_{S C \text {,set }}$ is a trade-off between energy and cost effectiveness. In fact, reducing the $t_{S C \text {,set }}$ below $15^{\circ} \mathrm{C}$ would require extra cooling capacity for the DMS at high outdoor temperature, or would give rise to lower $\mathrm{COP}_{\mathrm{DMS}}$. Work is in progress about an optimization of the operating variables for the $\mathrm{CO}_{2}$ booster with DMS system, here including the $t_{S C \text {,set }}$ value. Preliminary results suggest to limit this variable to the minimum value of $15^{\circ} \mathrm{C}$.

For the full exploitation of subcooling, suitable control rules on the high pressure $p_{G C}$ in transcritical conditions can be adopted in order to maximize the COP of the overall system $\left(\mathrm{CO}_{2}\right.$ booster plus subcooler) leading to the optimised cycle, named OBDMS, showed in Fig.1. Typically, the optimal rejection pressure is reduced $\left(\Delta p_{G C}\right)$ and, in turn, the specific work of high stage compressors $\left(\Delta w_{H S}\right)$, providing additional advantages in the overall performance. The procedure followed to optimize the overall system is described in the next section.

\section{OPTIMISED BOOSTER SYSTEM}

In the optimised scheme of booster system with DMS, parameters such as the gas cooler pressure can be specifically set in order to maximise the overall COP of the plant.

As a starting point, it is important to highlight which parameters affect the COP in a transcritical booster system with DMS. The COP for the booster with flash gas valve without mechanical subcooling (B) is given by the following expression:

$$
C_{B}=\frac{Q_{L T}+Q_{M T}}{W_{L S}+W_{H S}}=\frac{\left(\dot{m}_{L T}+\dot{m}_{M T}\right) \Delta h_{\text {evap }}}{\dot{m}_{L T} w_{L S}+\dot{m}_{H S} w_{H S}}
$$

where $Q_{L T}$ e $Q_{M T}$ are the cooling capacities at the low and medium evaporating level respectively, $\dot{m}_{L S}$ is the refrigerant mass flow rate of the low stage (coincides with LT) and $\dot{m}_{H S}$ is the high stage flow rate (flash gas included). The refrigerating capacity of the system is estimated neglecting the useful superheating at the evaporators, which has to be reduced as much as possible. Due to the shape of the saturation curve, the enthalpy difference $\Delta h_{\text {evap }}$ as indicated in Figure 2 differs by less than $0.5 \%$ when comparing LT and MT, and for this reason it can be considered equal for the two temperature levels in Eq. (3). The enthalpy difference $\Delta h_{\text {evap }}$ has, with good approximation, the same value at the two evaporating levels. The terms denoted by $w$ are the specific compressor works of the two stages.

Dividing numerator and denominator by the term $\left(\dot{m}_{L T}+\dot{m}_{M T}\right)$, i.e. the useful refrigerant flow, and taking into account the mass balance at the liquid receiver, the following expression can be derived:

$$
C O P_{B}=\frac{\Delta h_{\text {evap }}}{\varphi w_{L S}+\frac{1}{\psi} w_{H S}}
$$

where the non-dimensional parameters $\varphi$ and $\psi$ are defined as:

$$
\begin{aligned}
& \varphi=\frac{\dot{m}_{L T}}{\dot{m}_{L T}+\dot{m}_{M T}} \\
& \psi=1-x_{\text {rec }}
\end{aligned}
$$


and the parameter $\varphi$ is null in a standard one-stage cycle while $\psi$ is the complementary to the vapour quality $x_{\text {rec }}$ at the receiver inlet.

When a DMS unit is in use in a booster system, the subcooling has basically the effect of lowering the amount of flash gas at the receiver (status 3 shifts to 3 ' in figure 2) while the specific cooling capacities at the two evaporating levels do not change (same status 6 in figure 2). Thus, the power elaborated by the high stage compressors is reduced as the mass flow rate of flash gas decreases. Now the COP takes into account the work required by the subcooler and gives the following expression:

$$
C O P=\frac{\Delta h_{\text {evap }}}{\varphi w_{L S}+\frac{1}{\psi}\left(w_{H S}+\frac{\Delta h_{\text {sub }}}{C O P_{D M S}}\right)}
$$

where $C O P_{D M S}$ is the coefficient of performance of the DMS unit and $\Delta h_{\text {sub }}$ the subcooling degree (Fig. 2).

If specific quantities are considered, the benefit, which is still on the reduction of the high stage electrical power, can be explained by the increase of $\psi$ and the reduction of $w_{H S}$. Conversely, it should be noticed that a shift of the inlet point 0 on the ( $p$ - $h$ ) chart (Fig. 2) towards a higher compressor inlet temperature 0 ' occurs, that yields a slight increment of the compressor work if the $p_{G C}$ is the same as in the basic booster (B). However, this effect is small when compared to the advantages achieved.

Finally, it can be proven that, once the plant operation conditions are defined (i.e. the parameters of Table 1, the compressors' efficiency, the COP of the DMS system and the cooling load ratio coefficient $\varphi$ which, on yearly averaged basis, is calculated as 0.176 for the considered plant), the COP defined in Eq. (7) essentially depends on three variables:

$$
C O P=f\left(p_{G C}, \Delta h_{\text {sub }}, t_{\text {ext }}\right)=f\left(p_{G C}, \Delta t_{\text {sub }}, t_{\text {ext }}\right)
$$

i.e. the outdoor temperature $t_{e x t}$, which is the heat rejection temperature for both booster and DMS cycles, the gas cooler pressure $p_{G C}$ and the subcooling degree $\Delta t_{\text {sub }}$.

Simulations have been carried out for outdoor temperature $t_{\text {ext }}$ ranging from $26^{\circ} \mathrm{C}$ to $38^{\circ} \mathrm{C}$ with a $1 \mathrm{~K}$ step, in order to identify the couple of controllable variables $\left(p_{G C}, \Delta t_{s u b}\right)_{o p t}$ that maximizes the COP in transcritical regime. The following ranges have been considered: $p_{G C}$ between 75 bar and 110 bar with a 0.5 bar step; $\Delta t_{\text {sub }}$, with a $2.5 \mathrm{~K}$ step, between the lowest value of $2.5 \mathrm{~K}$, and an upper value, which is the one necessary to approach the subcooler outlet set point temperature.

By interpolation of the results, Eq. (9) is derived, which can be used to choose the most effective (highest COP achievable) $p_{G C}$ value for every value of $t_{\text {ext }}$ and once $\Delta t_{\text {sub }}$ is known after the choice of the DMS size as described in Section 4.1:

$$
p_{G C}^{o p t}\left(t_{e x t}, \Delta t_{\text {sub }}\right)=c_{1} t_{\text {ext }}^{3}+c_{2} \Delta t_{\text {sub }}^{3}+c_{3} t_{\text {ext }}^{2}+c_{4} \Delta t_{\text {sub }}^{2}+c_{5} t_{\text {ext }}+c_{6} \Delta t_{\text {sub }}+c_{7} t_{\text {ext }}^{2} \Delta t_{\text {sub }}+c_{8} t_{\text {ext }} \Delta t_{\text {sub }}^{2}+c_{9} t_{\text {ext }} \Delta t_{\text {sub }}
$$

whose coefficients are:

$$
\begin{array}{lll}
c_{1}=3.4333 \cdot 10^{-4} & c_{2}=-5.7308 \cdot 10^{-4} & c_{3}=-2.9695 \cdot 10^{-2} \\
c_{4}=-3.83115 \cdot 10^{-2} & c_{5}=3.36129 & c_{6}=-2.7487 \cdot 10^{-1} \\
c_{7}=-2.24931 \cdot 10^{-3} & c_{8}=2.32526 \cdot 10^{-3} & c_{9}=5.98662 \cdot 10^{-2}
\end{array}
$$

Values estimated by interpolation (Eq. 9) have a maximum deviation of $1 \%$ against the original $p_{G C}$ values from the model.

As an example, Fig. 4 depicts how the COP varies with the gas cooler pressure for a given subcooling degree $(10 \mathrm{~K})$ and for a set of outdoor temperature values (coloured lines). 


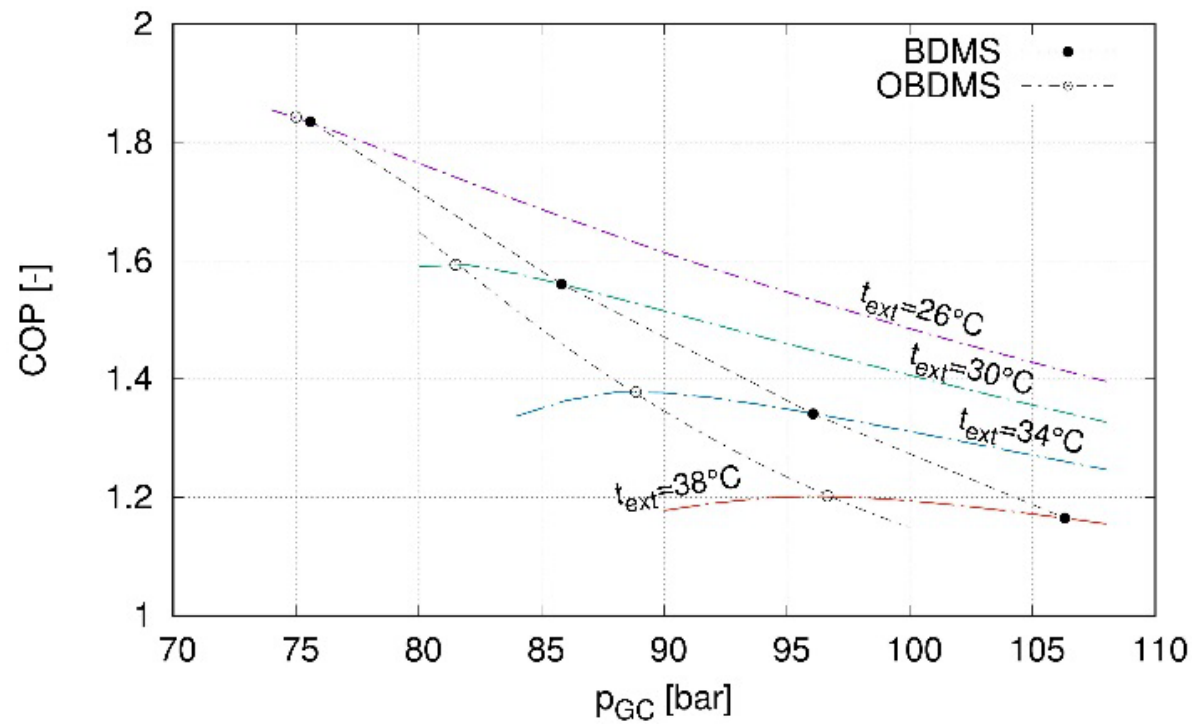

Figure 4: Overall plant COP vs. gas cooler pressure for a set of outdoor temperature values and $\Delta t_{\text {sub }}=10 \mathrm{~K}$.

When $t_{\text {ext }}$ is above $27^{\circ} \mathrm{C}$, the COP curve shows a maximum in correspondence of an optimum value for the gas cooler pressure (empty dots). For the sake of comparison, the values of the gas cooler pressure defined by Eq. (1) are marked in solid dots. When $t_{e x t}$ is below $27^{\circ} \mathrm{C}$, the optimal pressure coincides with the lowest value in the pressure range, namely 75 bar, as no maximum appears (Fig. 4). The predicted COP increments (OBDMS vs BDMS) range from $0.40 \%$, at $26^{\circ} \mathrm{C}$ outdoor temperature, to $3.2 \%$ at $38^{\circ} \mathrm{C}$. This result underlines the chance to optimise the pressure, especially at high outdoor temperature.

When performing this investigation at various subcooling degrees, comparing $p_{G C}^{o p t}$ (Eq. 9) with $p_{G C}$ (Eq. 1) it is found that the chance to reduce the gas cooler pressure increases with the subcooling degree, when also the influence of the outdoor temperature is higher. Fig. 5 shows the reduction achievable $\left(\Delta p_{G C}\right)$ as a function of the outdoor temperature for a set of subcooling degrees. At the lowest subcooling degree $\Delta t_{\text {sub }}=2.5 \mathrm{~K}$, the influence of the outdoor temperature is slighter and a maximum of around 4.5 bar appears between 36 and 37 ${ }^{\circ} \mathrm{C}$. Reducing $t_{\text {ext }}$ below $27^{\circ} \mathrm{C}$ in the presence of subcooling, the $p_{G C}$ value is kept at the minimum value of 75 bar, until the smooth transition to subcritical conditions begins.

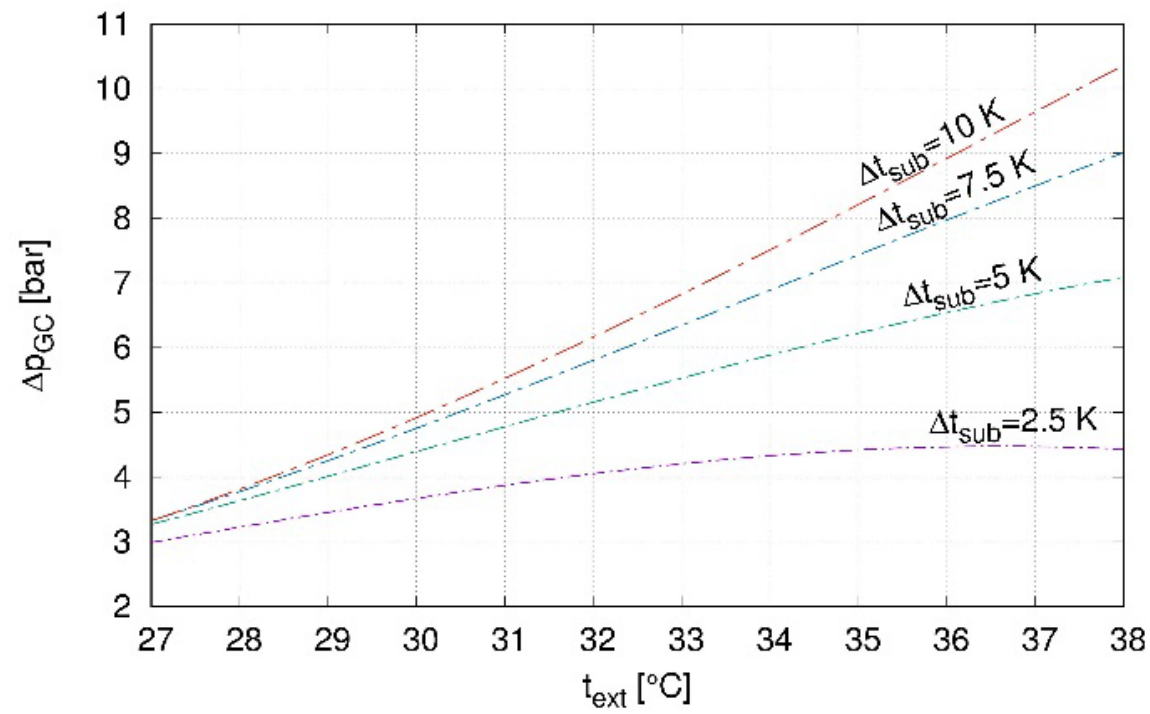

Figure 5: Achievable reduction in the gas cooler pressure vs. outdoor temperature for a set of subcooling degrees.

Subcooling is intended to improve the COP of the plant. The influence of the subcooling degree on the COP for various outdoor temperature values is reported in Fig. 6. As stated above, the upper limit for the subcooling degree, which has been considered in the simulations, is imposed by the subcooler outlet set point temperature $t_{S C, \text { set }}\left(15^{\circ} \mathrm{C}\right)$. 


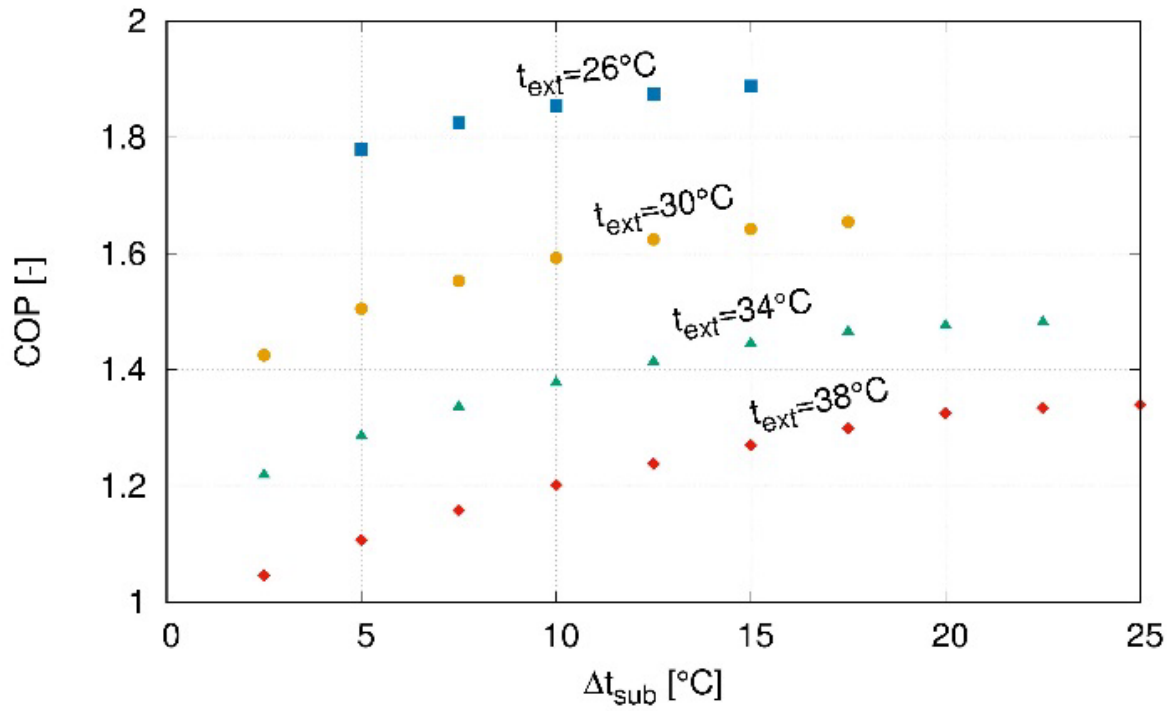

Figure 6: Overall plant COP vs. $\Delta t_{\text {sub }}$ for a set of outdoor temperatures. Each case is evaluated at optimum gas cooler pressure (OBDSM).

It can be observed that in this plant, for each outdoor temperature, the COP increases approaching the maximum value approximately in correspondence of the maximum achievable subcooling degree. The COP values tend to stabilize but it is not proven that higher subcooling degrees don't yield additional advantages.

\section{YEARLY PERFORMANCE SIMULATIONS}

Once the optimization of the heat rejection pressure has been performed, the comprehensive model has been used to carry out simulations for a whole year, with an hourly time step, to predict the annual electrical energy demand of the benchmark system considered. The mild weather data typical of Modena (Italy) has been considered. It is important to point out that, for the sake of annual energy demand prediction, the booster model includes the electrical demand for auxiliaries, which has been calibrated against monitored data and accounts on average around $3.2 \mathrm{~kW}$ [30]. This leads to a reduction of $31.6 \%$ for the COP at optimal conditions ( $p_{G C}$, $\left.\Delta t_{\text {sub }}\right)_{\text {opt }}$ with respect to the value of Eq. (7) at $26^{\circ} \mathrm{C}$, and of $26.2 \%$ at $38^{\circ} \mathrm{C}$. As a start, a limit size of the DMS unit has been sought, then the performance of the OBDMS solution has been compared to that of other system layouts operating under the same conditions, which are essentially the time dependent cooling load (from the simulation of display cabinets and cold rooms) and weather.

\subsection{DMS sizing}

When it comes to DMS, once the optimum conditions for the given plant are determined, a further important aspect to investigate is the choice of the most suitable cooling capacity $Q_{\text {sub }}$ of the DMS device, which can be compared to the maximum value of the refrigerating capacity estimated by the model for the main cycle on the basis of display cabinets and cold rooms operation by the ratio:

$$
\alpha=\frac{Q_{\text {sub }}}{Q_{L T \max }+Q_{M T \max }}
$$

In fact, the overall performance of the system is not the only parameter to focus on. Special attention to prevent oversizing the DMS unit must be given so as to avoid high investment costs that would yield negligible advantages. Several annual simulations have been run varying the cooling capacity $Q_{\text {sub }}$ between $6 \mathrm{~kW}$ and 24 $\mathrm{kW}$ with a step of $3 \mathrm{~kW}$, in order to determine the most suitable size of the subcooler. Given that the total peak cooling capacity of the considered system is of $46.5 \mathrm{~kW}$, the value of $\alpha$ ranges from $12.9 \%$ to $51.6 \%$. Furthermore, the influence of the parameter $\varphi$ defined in Eq. 5, practically the ratio of the Low Temperature cooling load to the global one, has been investigated, especially in the view of comparing single temperature systems and two temperature ones. In order to do so, keeping the global average capacity constant, the LT and 
MT capacities have been varied to obtained values of $\varphi$ in the range from 0 (single MT temperature system) to 0.176 (the actual configuration considered) to 0.211 (the actual system with the maximum LT capacity exploited). The energy saving in the total energy demand with auxiliaries has been evaluated, comparing the optimized OBDMS system and the one without DMS at mild climate conditions (whose temperature bins are named “Modena” in Fig. 9) for several sizes of the DMS system. The results are reported in Fig. 7.

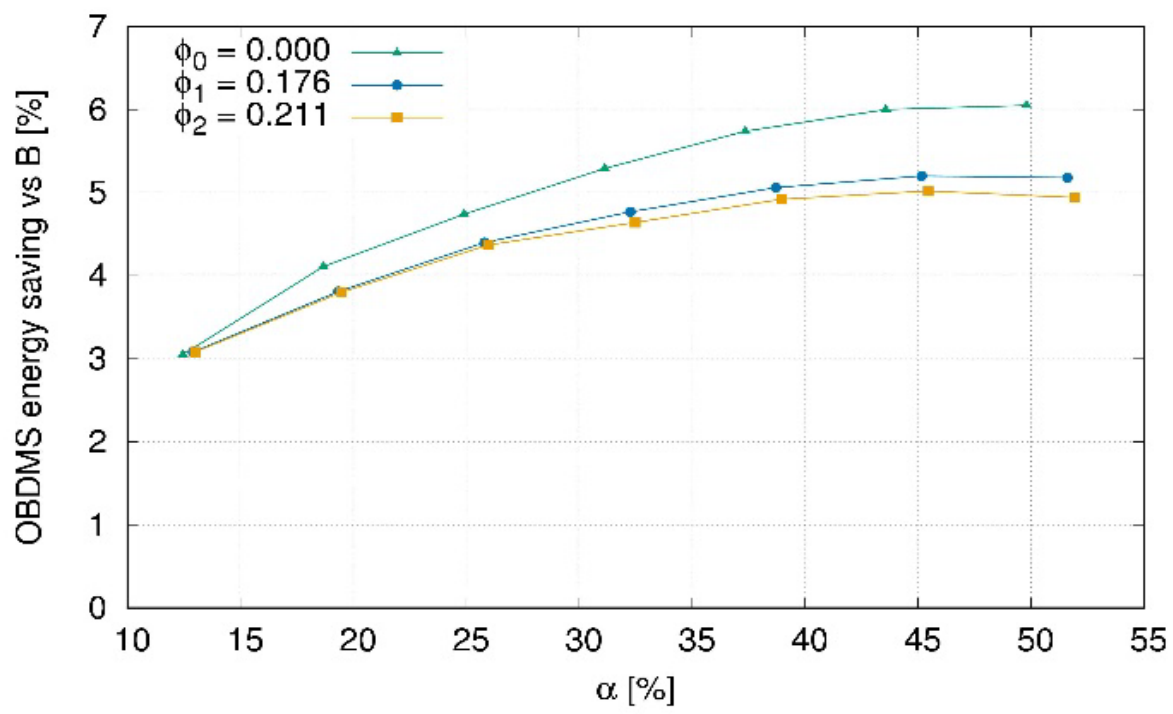

Figure 7: Overall plant energy savings vs. case B against maximum available cooling capacity of the DMS unit, for a set of annual average values of $\varphi$.

First of all, it appears that the energy saving gained through mechanical subcooling is higher in single temperature systems, while when a two temperature system is considered the influence of the BT on the global cooling capacity is almost negligible, in the range of the commonly found values. This result explains the discrepancy between the values reported in the literature on single temperature systems and the actual effect of subcoolers in booster systems for commercial refrigeration. A favourable choice at the climate conditions considered is a subcooler with a maximum available cooling capacity corresponding to $\alpha$ around $45 \%$. Again, there is not a marked maximum of the curve, thus a possible choice of the DMS size below the most favourable in terms of energy use goes with a cost analysis.

\subsection{DMS performance comparison against other schemes}

Subcooling can be achieved not only by employing a dedicated mechanical system, but also through taking advantage of chilled water usually available for air conditioning purposes [12]. A comparison between a DMS scheme, a subcooling scheme with HVAC chilled water integration and the typical configuration with parallel compression, which is commonly considered as an alternative to subcooling, is thus carried out.

The results of this evaluation apply for a mild weather (whose temperature bins are named "Modena climate" in Fig. 9). Simulations are carried out for a whole year with an hourly time step.

The configurations investigated are all booster systems with:

- B (reference case): basic system with flash gas valve, $p_{G C}$ chosen with Eq. (1) at transcritical conditions;

- BPC: solution with parallel compressor (Bitzer 4JTC-15K) and a specific control rule for $p_{G C}[30]$ :

$$
p_{G C}=\max \left[75 ;\left(1.75 t_{G C}+22.13\right)\right][\mathrm{bar}]
$$

- BSC: sub-cooler with chilled water heat exchanger, $p_{G C}$ chosen with Eq. (1) at transcritical conditions;

- BDMS: Dedicated Mechanical Subcooling, of which the $\mathrm{COP}_{\mathrm{DMS}}$ is given in Fig. 3; $p_{G C}$ chosen with Eq. (1) at transcritical conditions;

- OBDMS: BDMS with gas cooler pressure optimisation, following Eq. (9) at transcritical conditions. 
The main operating parameters are collected in Table 1 ; the subcooler size is such that $\alpha=45 \%$, and the set point temperature of $\mathrm{CO}_{2}$ at the exit of the subcooler $t_{S C \text {,set }}$ is imposed at $15^{\circ} \mathrm{C}$. The same activation temperature $t_{\text {act }}$ has been chosen for all the performance enhancement devices considered, i.e. PC, SC, DMS; this value has been set to $19^{\circ} \mathrm{C}$, which is the lower limit of the transition zone from subcritical to transcritical operation. The receiver pressure is kept at 35 bar for all the configurations.

The electrical energy utilization of the commercial refrigeration unit with auxiliaries of a whole year, in the cases analysed, is reported in Table 2. The energy consumption of the BPC is estimated as the sum of the electrical energy consumption of all the compressors, here included the parallel one-. As regards the BSC, the electrical consumption of the subcooling function by the HVAC chiller is estimated by dividing at each time step the cooling power at the subcooler by the COP of the water chiller at the operating conditions at that specific time [12].

Table 2. Comparison between the annual electrical energy demand of the cases analysed.

\begin{tabular}{|c|c|c|c|c|}
\hline \multicolumn{5}{|c|}{ Annual electrical energy demand [MWh] } \\
\hline Case & Booster & Subcooler & Total & Energy saving [\%] \\
\hline B & 128.7 & 0 & 128.7 & 0.0 \\
\hline BPC & 123.5 & 0 & 123.5 & 4.0 \\
\hline BSC & 116.9 & 8.0 & 124.9 & 2.9 \\
\hline BDMS & 116.9 & 5.6 & 122.5 & 4.8 \\
\hline OBDMS & 116.1 & 5.9 & 122.0 & 5.2 \\
\hline
\end{tabular}

It can be noticed that the BDMS scheme, in this example of application and climate, is a bit more effective than the parallel compression scheme BPC and, if optimised, a further small improvement can be achieved. The optimized DMS scheme allows a $5.2 \%$ energy saving compared to the basic solution. The SC scheme, which exploits the cooling capacity provided by a chiller for air conditioning purposes, gives a poorer energy saving, due to the lower COP of the water chiller (its evaporating temperature is around $2{ }^{\circ} \mathrm{C}$ ) and the use of an intermediate fluid. However, this solution has the advantage of reducing the equipment cost.

The results, in electrical energy demand terms, are also presented on a monthly basis in the histogram of Fig. 8. The improvement respect to the basic booster is obtained, of course, during the warm and hot months when transcritical operation occurs.

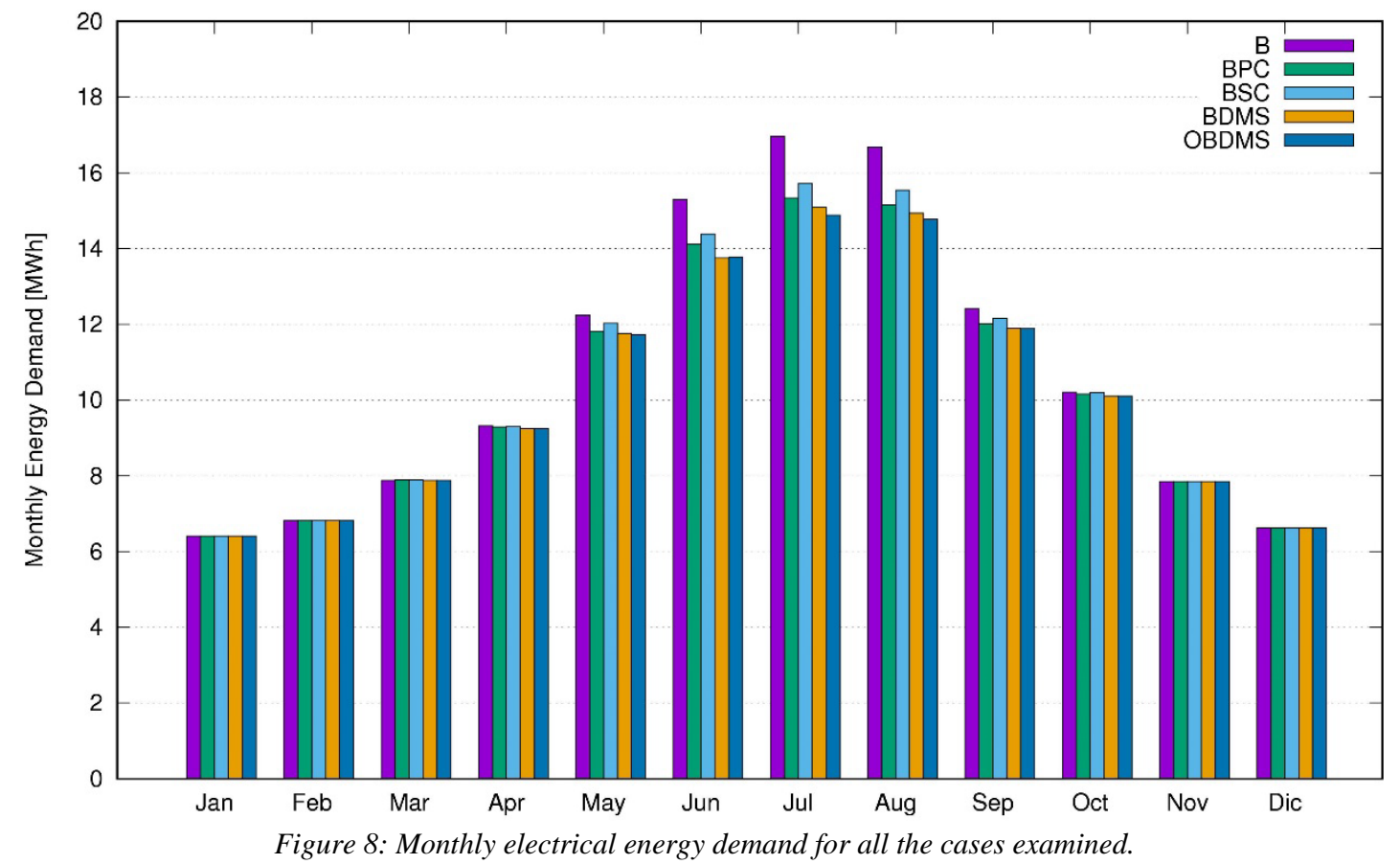




\subsection{Extreme hot weather application}

The OBDMS system is expected to give the best benefit at high outdoor temperature, thus a further investigation is carried out in hot climate conditions, with higher average outdoor temperature. A R1234yf DMS unit combined to a $\mathrm{CO}_{2}$ booster system is again considered, with optimised gas cooler pressure control, at three different hot weather locations:

1. Cairo, Egypt

2. Bangalore, India

3. Bangkok, Thailand

The distribution of the outdoor air temperature at these locations, and at Modena which has been examined in the previous section, is represented in Fig. 9.

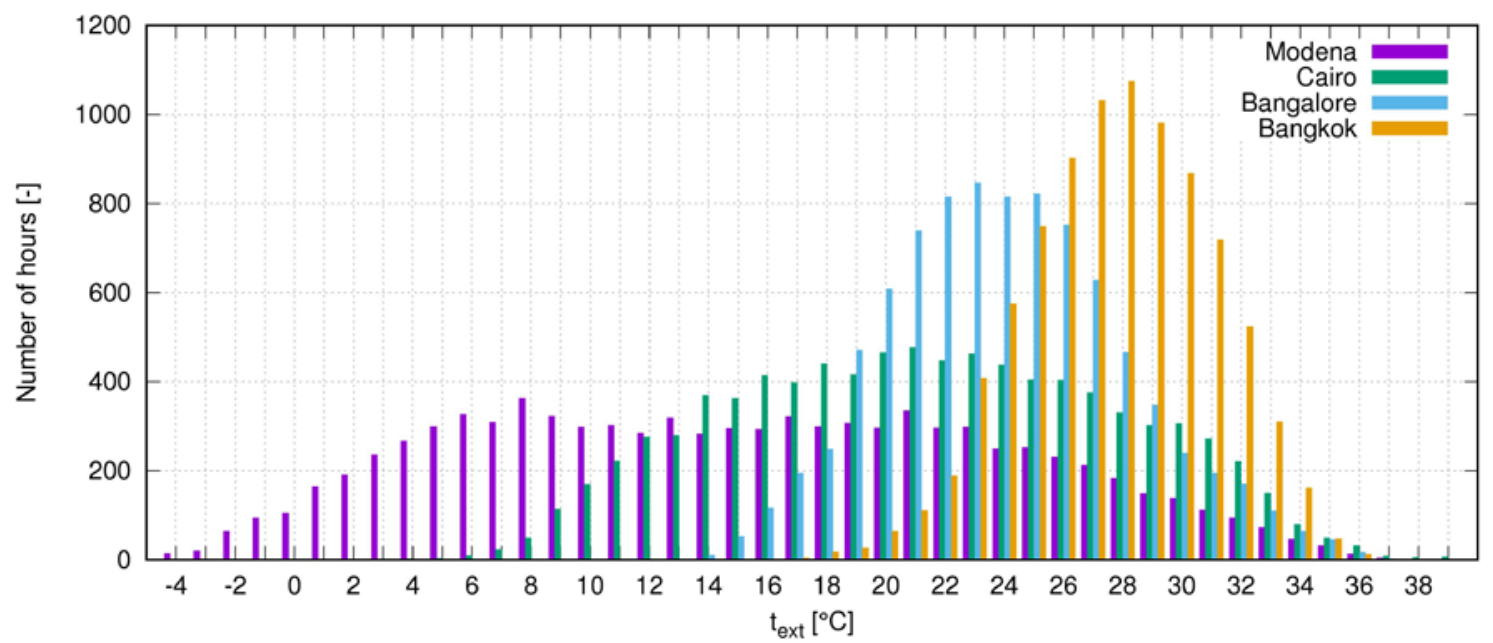

Figure 9: Temperature bins for the selected locations.

It can be observed that, especially for Bangalore and Bangkok, most of the year is characterized by high outdoor temperature, with small variation among the seasons. In this kind of climate condition, DMS is exploited for most of the working hours. In fact, setting the activation temperature $t_{\text {act }}$ equal to $19^{\circ} \mathrm{C}$, the DMS unit is active for $61.7 \%$ of the working hours in Cairo, 90.3\% in Bangalore and 99.6\% in Bangkok, while only for $35.9 \%$ in Modena.

The same cases simulated in the previous section are analysed for the locations aforementioned, varying the refrigerating capacity of the DMS spanning from $\alpha=13 \%$ to $52 \%$. The most effective size of the DMS has been found at $\alpha=45.1 \%$ in Cairo, similarly at what was found for the milder climate conditions, while a lower size of the DMS can be considered for the warmer climate of Bangalore and Bangkok (Fig. 10). However again there is not a marked maximum of the curve, especially at the hotter climate where the DMS is operating almost continuously. Therefore, the choice of the DMS size goes also with a thorough cost analysis. 


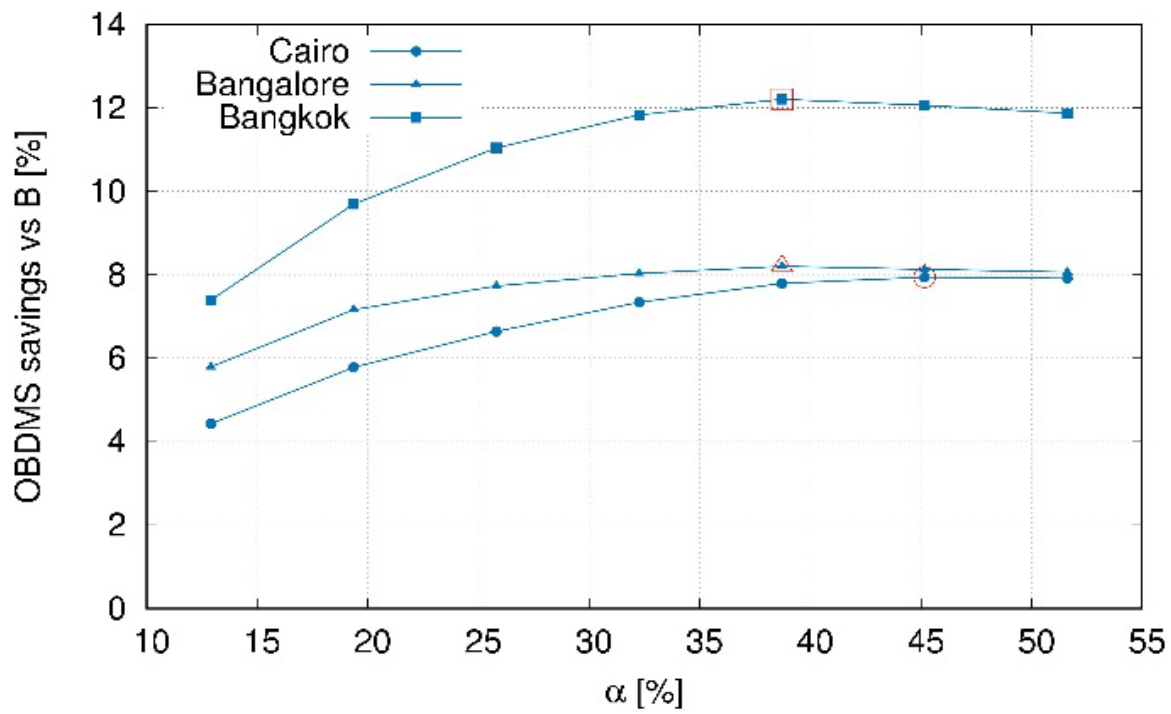

Figure 10: Overall plant energy savings vs. basic Booster (B) for a set of maximum available cooling capacity of the DMS unit for the hot climates considered.

The annual energy demand and the corresponding energy saving versus the reference case, i.e. the basic booster $\mathrm{B}$, are summarised in Table 3. The simulations have been run at $\alpha=45.1 \%$ in Cairo and $\alpha=38.7 \%$ in Bangalore and Bangkok.

Table 3. Total annual energy demand and energy saving (ES) vs the basic booster (B)

\begin{tabular}{lcccccc}
\hline \multirow{2}{*}{ Case } & \multicolumn{2}{c}{ Cairo } & \multicolumn{2}{c}{ Bangalore } & \multicolumn{2}{c}{ Bangkok } \\
\cline { 2 - 7 } & Total [MWh] & ES [\%] & Total [MWh] & ES [\%] & Total [MWh] & ES [\%] \\
\hline B & 153.0 & 0.0 & 160.2 & 0.0 & 184.0 & 0.0 \\
BPC & 143.7 & 6.0 & 151.2 & 5.6 & 168.3 & 8.5 \\
BSC & 145.9 & 4.6 & 153.2 & 4.3 & 171.2 & 7.0 \\
BDMS & 141.8 & 7.3 & 148.1 & 7.5 & 164.0 & 10.8 \\
OBDMS & 140.8 & 7.9 & 147.1 & 8.2 & 161.5 & 12.2 \\
\hline
\end{tabular}

BDMS always performs slightly better than BPC, while the BSC scheme has to be considered only where an extra cooling capacity can be gained from an existing HVAC chiller at no investment cost. The energy saving increases up to about $11 \%$ with BDMS at the hottest climate (Bangkok). As the climate is hotter and pretty much constant throughout the year, an additional $1.4 \%$ is yielded with the gas cooler pressure control optimisation, thus an annual energy improvement of $4.0 \%$ vs BPC solution, results that are in agreement with data from the literature (Catalan-Gil et al., 2019).

\section{CONCLUSIONS}

Dedicated Mechanical Subcooling is indeed an effective solution to enhance the performance of $\mathrm{CO}_{2}$ booster systems. Energy saving can be further boosted by reducing the gas cooler pressure of the $\mathrm{CO}_{2}$ plant, especially at high outdoor temperature and with high subcooling degree. The gas cooler pressure can be reduced up to 10 bar at $37.5{ }^{\circ} \mathrm{C}$ outdoor temperature and with a $10 \mathrm{~K}$ subcooling degree. Subcooling allows to increase significantly the COP of the system at high outdoor temperature. However, there is an optimum subcooling degree beyond which the COP doesn't reflect any further improvement. This value of subcooling degree gets higher as the outdoor temperature increases. As far as the DMS size is concerned, also the cooling capacity of the subcooler has to be carefully chosen, given that beyond a certain value no further improvements are encountered in the energy saving. An analysis in non-dimensional units is given for the choice of the best size, which has to be supported by a cost analysis. Finally, DMS showed to be more effective than parallel compression, even if both configurations are worth being considered at warm-hot climate conditions. Similarly, subcooling performed at the expenses of a water chiller for HVAC shows to be a bit less effective 
in terms of energy use, but possibly more attractive in terms of cost analysis given that investment costs can be reduced.

\section{ACKNOWLEDGMENT}

The research leading to these results has received funding from the MIUR of Italy within the framework of the PRIN2017 project « The energy flexibility of enhanced heat pumps for the next generation of sustainable buildings (FLEXHEAT)», grant 2017KAAECT.

\section{REFERENCES}

[1] Matthiesen O., Madsen K., Mikhailov A., 2010. Evolution of $\mathrm{CO}_{2}$ systems design based on practical experiences from supermarket installations in Northern Europe. In: Proc. 9 ${ }^{\text {th }}$ IIR Gustav Lorentzen conference on natural working fluids, $12^{\text {th }}-14^{\text {th }}$ April, Sydney, Australia. Paper ID: 81.

[2] Shecco, 2018. Technical report on energy efficiency in HFC-free supermarket refrigeration. http://publication.shecco.com/publications/view/207. [accessed 16/03/2020]

[3] Llopis R., Nebot-Andrés L., Sánchez D., Catalán-Gil J., Cabello R., 2018. Subcooling methods for $\mathrm{CO}_{2}$ refrigeration cycles. A Review. Int. J. Refrig., 93, 85-107. https://doi.org/ 10.1016/j.ijrefrig.2018.06.010

[4] Cavallini A., Cecchinato L., Corradi M., Fornasieri E., Zilio C., 2005. Two-stage transcritical carbon dioxide cycle optimisation :A theoretical and experimental analysis. Int. J. Refrig. 28, 1274-1283. https://doi.org/10.1016/j.ijrefrig.2005.09.004

[5] Karampour M., Sawalha S., 2014. Investigation of using internal heat exchangers in $\mathrm{CO}_{2}$ trans-critical booster system. In: $11^{\text {th }}$ IIR Gustav Lorentzen Conference, Hangzhou, China, 453-460.

[6] Sharma V., Fricke B., Bansal P., 2014. Comparative analysis of various $\mathrm{CO}_{2}$ configurations in supermarket refrigeration systems. Int. J. Refrig., 46, 86-99. https://doi.org/10.1016/j.ijrefrig.2014.07.001

[7] Torrella E., Sanchéz D., Llopis R., Cabello R., 2011. Energetic evaluation of an internal heat exchanger in a $\mathrm{CO}_{2}$ transcritical refrigeration plant using experimental data. Int. J. Refrig., 34, 40-49. https://doi.org/10.1016/j.ijrefrig.2010.07.006

[8] Catalán-Gil J., Nebot-Andrés L., Sánchez D., Llopis R., Cabello R., Calleja-Anta D. 2020. Improvements in $\mathrm{CO}_{2}$ booster architectures with different economizer arrangements. Energies, 13, 1271. https://doi.org/10.3390/en13051271

[9] Elbel, S. , Hrnjak, P., 2004. Effect of internal heat exchanger on performance of transcritical $\mathrm{CO}_{2}$ systems with ejector. International Refrigeration and Air Conditioning Conference. Purdue (IL, USA), Paper 708. https://docs.lib.purdue.edu/iracc/708/

[10] Joneydi Shariatzadeh, O., Abolhassani, S.S., Rahmani, M., Ziaee Nejad, M., 2016. Comparison of transcritical $\mathrm{CO}_{2}$ refrigeration cycle with expander and throttling valve including/excluding internal heat exchanger: Exergy and energy points of view. Appl. Therm. Eng. 93, 779-787. https://doi.org/10.1016/j.applthermaleng.2015.09.017

[11] Polzot A., D'Agaro P., Gullo P., Cortella G., 2016. Modelling commercial refrigeration systems coupled with water storage to improve energy efficiency and perform heat recovery. Int. J. Refrig., 69, 313-323. https://doi.org/10.1016/j.ijrefrig.2016.06.012

[12] Cortella G., D’Agaro P., Coppola M.A., 2020. Transcritical $\mathrm{CO}_{2}$ commercial refrigeration plant with adiabatic gas cooler and subcooling via HVAC: Field tests and modelling. Int. J. Refrig., 111, 71-80. https://doi.org/10.1016/j.ijrefrig.2019.11.022

[13] Eikevik, T.M., Bertelsen, S., Haugsdal, S., Tolstorebrov, I., Jensen, S., 2016. $\mathrm{CO}_{2}$ refrigeration system with integrated propane subcooler for supermarkets in warm climate. In: Proc. $12^{\text {th }}$ IIR Gustav Lorentzen Natural Working Fluids Conference. Edinburgh (UK). Refrig. Sci. Technol., 2016, 211-218. https://doi.org/ 10.18462/iir.gl.2016.1031

[14] Hafner, A., Hemmingsen, A.K., 2015. R744 refrigeration technologies for supermarkets in warm climates. In: Proc. 24 ${ }^{\text {th }}$ International Congress of Refrigeration, ICR 2015 Yokohama, Japan. Refrig. Sci. Technol., 2015, 2313-2320. https://doi.org/10.18462/iir.icr.2015.0168 
[15] Llopis, R., Cabello, R., Sánchez, D., Torrella, E., 2015. Energy improvements of $\mathrm{CO}_{2}$ transcritical refrigeration cycles using dedicated mechanical subcooling. Int. J. Refrig. 55, 129-141. https://doi.org/ 10.1016/j.ijrefrig.2015.03.016

[16] Dai, B., Liu, S., Sun, Z., Ma, Y., 2017. Thermodynamic performance analysis of $\mathrm{CO}_{2}$ transcritical refrigeration cycle assisted with mechanical subcooling. Energy Proc. 105, 2033-2038. https://doi.org/10.1016/j.egypro.2017.03.579

[17] Liu S., Lu. F., Dai B., Nian V., Li H., Qi.H., Li J., 2019. Performance analysis of two-stage compression transcritical $\mathrm{CO}_{2}$ refrigeration system with R290 mechanical subcooling unit. Energy, 189, 116-143. https://doi.org/10.1016/j.energy.2019.116143

[18] Nebot-Andrés, L., Llopis, R., Sánchez, D., Cabello, R., 2016. Experimental evaluation of a dedicated mechanical subcooling system in a $\mathrm{CO}_{2}$ transcritical refrigeration cycle. In: Proc. $12^{\text {th }}$ IIR Gustav Lorentzen Natural Working Fluids Conference, GL 2016. Edinburgh (UK). Refrig. Sci. Technol. 2016, 965-972. https://doi.org/10.18462/iir.gl.2016.1162

[19] Llopis R., Nebot-Andrés L., Cabello R., Sánchez D., Catalán-Gil J., 2016. Experimental evaluation of a $\mathrm{CO}_{2}$ transcritical refrigeration plant with dedicated mechanical subcooling. Int. J. Refrig. 69, 361-368. https://doi.org/ 10.1016/j.ijrefrig.2016.06.009

[20] Gullo P., Elmegaard B., Cortella G., 2016. Energy and environmental performance assessment of R744 booster supermarket refrigeration systems operating in warm climates, Int. J. Refrig. 64, 61-79. https://doi.org/ 10.1016/j.ijrefrig.2015.12.016

[21] Beshr, M., Bush, J., Aute, V., Radermacher, R., 2016. Steady state testing and modeling of a $\mathrm{CO}_{2}$ twostage refrigeration system with mechanical subcooler. In: Proc. of the $12^{\text {th }}$ IIR Gustav Lorentzen Conference on Natural Refrigerants. Edinburgh (UK). Refrig. Sci. Technol. 893-900. https://doi.org/10.18462/iir.gl.2016.1146

[22] Bush, J., Beshr, M., Aute, V., Radermacher, R., 2017. Experimental evaluation of transcritical $\mathrm{CO}_{2}$ refrigeration with mechanical subcooling. Sci. Technol. Built Environ. 23 (6), 1-13. https://doi.org/10.1080/23744731.2017.1289056

[23] Mazzola, D., Sheehan, J., Bortoluzzi, D., Smitt, G., Orlandi, M., 2016. Supermarket application. Effects of sub-cooling on real R744 based trans-critical plants in warm and hot climate. Data Analysis. In: Proc. $12^{\text {th }}$ IIR Gustav Lorentzen Natural Working Fluids Conference, GL 2016. Edinburgh (UK). Refrig. Sci. Technol. 2016, 551-558. https://doi.org/ 10.18462/iir.gl.2016.1089

[24] Catalán-Gil J., Llopis R., Sánchez D., Nebot-Andrés L., Cabello R., 2019. Energy analysis of dedicated and integrated mechanical subcooled $\mathrm{CO}_{2}$ boosters for supermarket applications. Int. J. Refrig., 101, 1123. https://doi.org/10.1016/j.ijrefrig.2019.01.034

[25] Koeln, J.P., Alleyne, A.G., 2014. Optimal subcooling in vapor compression systems via extremum seeking control: theory and experiments. Int. J. Refrig. 43, 14-25. https://doi.org/ 10.1016/j.ijrefrig.2014.03.012

[26] Klein, S.A., Beckman, W.A., Duffie, J.A., 2010. TRNSYS 17, A Transient System Simulation Program, Solar Energy Laboratory, University of Wisconsin, Madison, USA.

[27] Polzot A., Gullo P., D’Agaro P., Cortella G., 2016. Performance Evaluation of a R744 Booster System for Supermarket Refrigeration, Heating and DHW. In: Proc. $12^{\text {th }}$ IIR Gustav Lorentzen Natural Working Fluids Conference, GL 2016. Edinburgh (UK). Refrig. Sci. Technol. 2016, 154-161. https://doi.org/10.18462/iir.gl.2016.1022

[28] Polzot A., D’Agaro P., Cortella G., 2017, Energy analysis of a transcritical $\mathrm{CO}_{2}$ supermarket refrigeration system with heat recovery. Enrgy Proced, 111:648-657, 2017. https://doi.org/10.1016/j.egypro.2017.03.227

[29] Cortella G., D’Agaro P., Coppola M.A., 2018. Simulations and field tests of a $\mathrm{CO}_{2}$ refrigerating plant for commercial refrigeration. In: Proc. $13^{\text {th }}$ IIR Gustav Lorentzen Conference on Natural Refrigerants, Valencia (E). Refrig. Sci. Technol., (June 2018), 556-563. https://doi.org/10.18462/iir.gl.2018.1215

[30] D’Agaro P., Coppola M.A., Cortella G., 2019. Field Tests, Model Validation and Performance of a $\mathrm{CO}_{2}$ Commercial Refrigeration Plant Integrated with HVAC System. Int. J. Refrig., 100, 380-391, https://doi.org/10.1016/j.ijrefrig.2019.01.030 
[31] CommONEnergy 2017. CommONEnergy, Converting EU Shopping Centres Into Beacons Of Energy Efficiency, http://www.commonenergyproject.eu [accessed 16/03/2020].

[32] Bell, I.H, Wronski, J., Quoilin, S., Lemort, V., 2014. Pure and Pseudo-pure Fluid Thermophysical Property Evaluation and the Open-Source Thermophysical Property Library CoolProp. Ind. Eng. Chem. Res. 53(6), 2498-2508. 